\title{
Community Oriented-Rural Tourism Development Model
}

\author{
Indra Bahadur Malla Thakuri ${ }^{1} \&$ Govind Nepal ${ }^{2}$
}

\author{
${ }^{1}$ Mewar University, Rajasthan, India \\ ${ }^{2}$ Tribhuvan University, Kathmandu, Nepal \\ Correspondence: Indra Bahadur Malla Thakuri, Mewar University, Rajasthan, India, E-mail: ibmalla@hotmail.com
}

Received: October 25, 2017

Accepted: October 29, 2017

Online Published: January 2, 2018

\begin{abstract}
Nepal is endowed with the majestic Himalayan ranges, including Mt. Everest, which is $8848 \mathrm{~m}$, is the world's highest mountain peak. Nepal is renowned world-wide as a prime tourist destination due to its unparalleled natural beauty; diverse bio-diversity; ethnic, lingual and social diversity; and historical and cultural wealth. There are many lakes, rivers, mountainous areas, museums, national parks, historical places, greenery forests, cultural heritages which become attractions to the tourists in Nepal. Rural setting is one of the most potential areas to promote the rural tourism where tourists can have opportunity to observe the rural setting, culture, life-style, social relationship, hospitality etc of rural people in Nepal. So, the study has developed the community oriented rural tourism development model covering the stages of development. The study was conducted in Lamjung, Tanahu and Nawalparasi districts among the home-stay operators, tourist experts and other tourism related stakeholders. Indepth interview was done with the respondents to collect their opinion about the best model of rural tourism. The study has developed the Community Oriented Rural Tourism Development Model (CO-RTDM) which has explained the seven stages of development.
\end{abstract}

Keywords: Community-Oriented, Development, Model, Tourism, Rural.

\section{Introduction}

Tourism is one of the productive business activities directed for the production of the goods and services. It provides goods and services to the customers (visitors, generally foreigners) and employment and income to the locals. Tourism has burgeoned worldwide in the last two and half decades and outshined traditional industries to become one of the world's largest and fastest growing economic activities (Pao, 2005). Tourism supplements the foreign earnings derived from trade in commodities and sometimes finance the import goods necessary for the growth of manufacturing sectors in the economy. Countries like USA, Japan, Germany, and the UK hold dominant position in outgoing tourism. Meanwhile, countries such as Italy, France, USA, Spain, Switzerland, and Greece possess strong positions in incoming tourism (Cottrel, 2003, p. 2). Nepal is the largest industry in the tourism attraction due to of its possessing eight of the ten highest mountains in the world; Nepal is a hotspot destination for mountaineers, rock climbers and people seeking adventure. The Hindu and Buddhist heritage of Nepal and its cool weather are also strong attractions.

Generally, tourism researchers have evaluated tourism attractions/resources from three different perspectives: 1) the ideographic perspective, 2) the organizational perspective, and 3) the cognitive perspective (Lew, 1994; Lew, 1987). The ideographic perspective is related to the supply component and often assesses tourism attractions/resources by asking public and private tourism professionals such as tourism stakeholders to ascertain which tourism resources or elements are the most important to tourists and to destination attractiveness. The organizational perspective is associated with the linkages component that focuses on the spatial and temporal nature of tourism attractions/resources. Lastly, the cognitive perspective is associated with the demand component. Most research from this perspective deals with the degree to which tourists are able to take risks in their travel experiences, 
depending on the different types of tourism attractions available. Any single approach may not cover and evaluate the entire tourism attraction system. Also, there are some limitations to each approach in terms of inappropriate classification methods (Leiper, 1990). Thus, cross perspectives or a combination of these perspectives are suggested. Eco-tourism, a sub-category of sustainable tourism, is perceived by many Japanese rural communities as a new way to attract visitors and stimulate local economies through generating tourism revenues while conserving the natural, social and cultural resources of communities. As a result, many communities have started to develop ecotourism. Rural communities that are trying to develop ecotourism are also challenged by the need to as a sub-system to understand and manage the complex relationship between community and extra-community stakeholder. In some cases, tourism has the potential to create negative impacts, especially if allowed to develop without proper planning. Gunn said and indicated that there is no other form of development 'that has so many far-reaching tentacles as tourism does'. Specifically, tourism can impact a community in ways that would, on the surface, appear to be unrelated to the tourism industry (Gunn, 1994)

Mutual, social and cultural interactions between residents and tourists are inevitable, since the tourist movements contribute to encountering different societies and areas, with an increasingly altering level of their differences. Thus, the quality of interaction between tourists and residents contributes to both tourists experience and perception of the visited destination and acceptance and tolerance of tourist by residents. Many elements of national cultures (values, norms or rules) have a considerable impact on tourists' behavior, their holiday expectations, satisfactions and consequently repeated visits (Reisinger \& Turner, 2003). Total quality management of tourist service provider can influence the tourists and it can motivate tourists' repeated visit and possibility to refer other too. Besides that other basic infrastructures are pre-requisite for the tourism development. Transportation is essential to tourism and a key determinant of destination development.

The extent and standard of infrastructure and services influence the decisions of tourists and the tourism industry, helping to establish overall flows between and within countries. Deficiencies and doubts about safety are likely to be an impediment to growth, but provision of an adequate transportation system can be a challenge for some states that lack resources for investment and regulation (Henderson, 2009, p. 199). Countries with poor safety records and without an appropriate transportation infrastructure and set of operators and services will be disadvantaged as tourist destinations and the topic acquires heightened relevance for some locations and markets. For example, it has been argued that Western tourists are most anxious about reliable and safe travelling when visiting smaller relatively unknown African and Asian locations (Khadaroo \& Seetanah, 2008). It should be the serious concern of Nepal Government also to ensure the safety and security of tourists in tourist destinations. Considering this fact, Nepal Government has formed the 'Tourist Police' to provide the security of tourists in tourist destinations. Besides that, there is need to promote the rural tourism by improving the infrastructure development of appropriate tourist destination. There are many places located in rural society which are appropriate for the tourist destination so need to identify the location for further process of planning, implementation and dissemination of tourist destination. The main aim of this study is to develop the community oriented rural tourism development model for the promotion of rural tourism of Nepal.

2. Material \& Method

The study was based on the qualitative design to develop the model. It has adopted the constructive approach to generate the ideas from the in-depth interview with tourism experts, tourism related business person, home-stay operators of Ghalegaun of Lamjung district, Pathra of Tanahu district, and Amaltari of Nawalparasi district. Semistructured interview was taken with the respondents to know their opinion regarding the appropriate technique to promote the rural tourism. Judgmental sampling technique was used to select the respondents. The respondents shared their experience and ideas which become important to develop the model. The collected data was transcribed on the basis of theme of study. Thematic analysis of qualitative data supported to develop the model.

\section{Result \& Discussion}

Several previous literatures have elaborated important theoretical tourism development models. Major tourism development theories and models are based on the evolutionary approach on the tourism development and the factors shaping it; i.e., different factors lead to the successful development of tourism in rural areas in the different stages of development. These theories are aiming to explain the development of tourism which can be adapted to the rural tourism development and analysis. There are several important tourism development theories that analyze the evolution of the tourism, which is based on the travel life-cycle (Butler \& Miossec, 1993; Butler, 1980). These theories describe the development of tourism in a cyclical pattern. According to these theories, the changes in the tourism market are happening not due to the economic, social, or physical reasons, but because of the changing nature of the tourism market and the changing tourists' motivation (Streimikiene \& Bilan, 2015, p. 23). 
According to George, Mair and Reid (2009), in order to assess rural tourism development model, one should first determine which factors have motivated the local community to develop rural tourism. These reasons are different in different areas. Some motives of tourism development are related to the economic problems and the necessity to find new business niches, while in other areas the main reasons of the development of rural tourism are based on the available motives, where tourism supply and demand factors play an important role in rural tourism development.

The rural tourism development model should reflect the multiple levels (Geels, 2004; Geels, 2002) and explain the economic transformation of the processes that take place in different levels of interaction: a niche (micro level), regimes (meso level), and landscape (macro level). Two different areas can specialize in the provision of the same services but have a completely different morphology (mountains or plains) and apply different rural regimes (Coenen \& Truffer, 2012). Rural regime means coordination between all rural actors and stakeholders in order to ensure the harmonious development of rural area (Randelli, Romei, \& Tortora, 2012). Therefore, it is necessary to have a better theoretical understanding of the key factors that determine the development of rural tourism in rural areas and the interaction between these factors. This makes it possible to reveal the reasons of disparities in rural tourism development in rural areas (Roberts \& Hall, 2001). On the fact of theoretical understanding of rural development model, the study has proposed the Community Oriented- Rural Tourism Development Model (CORTDM). This model is designed on the basis of result of primary data collected by the study. The conceptual design of this model is as given in Figure 1.

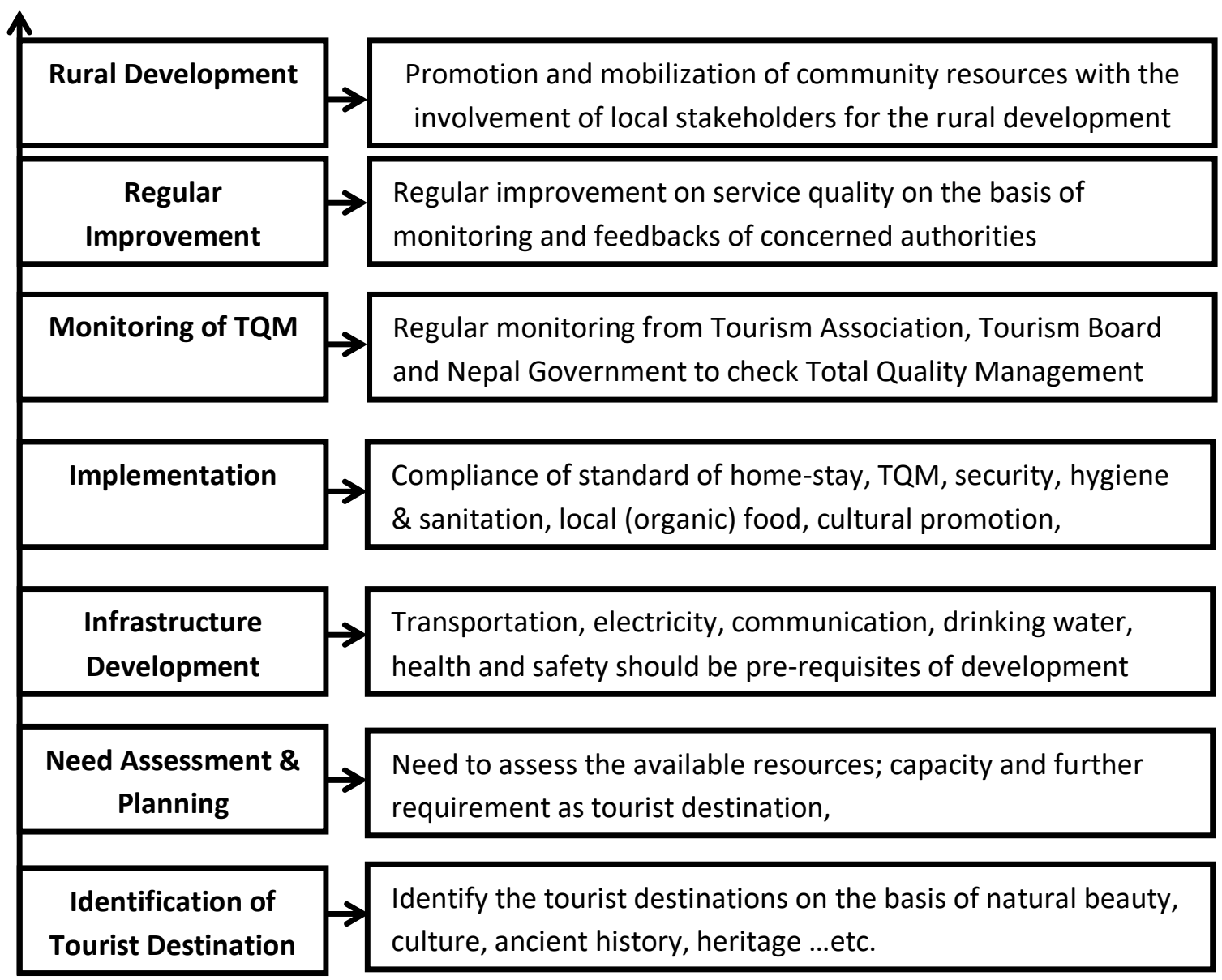

Figure 1: Community Oriented - Rural Tourism Development Model (CO-RTDM)

The model of rural development portrayed in Figure 1 shows the seven steps of development as follows:

First Stage: In the first step, it talks about the identification of tourist destinations. During the selection of tourist destinations, certain typical characteristics should be considered on the basis of natural beauty, culture of 
surrounding community, historical importance, religion etc which can be memorable story for the visitors. Second Stage: In the second phase, there should be need assessment of identified tourist destination. Capacity and vulnerability should be assessed. Available natural resources, public participation, involvement of stakeholders, presence of governmental and non-governmental organizations, potential investors for tourism development and possibility of other development along with tourism should be assessed. Then, need to prepare the development plan with close consultation of tourism experts.

Third Stage: Basic infrastructure should be developed as pre-requisites of rural tourism development. Transportation along with easy road access, electricity, communication, drinking water, basic health facility ...etc should be developed. Infrastructure can support to ensure the basic quality of services.

Fourth Stage: It is the most important stage of tourism development. This is the implementation stage so that the home-stay operators should compliance the basic standard of home-stay and other tourist focused hotel should also follow the related standard/guidelines. Total Quality Management (TQM) should be followed by security of tourists. Service providers should be aware on the security situation and provision and tourists should be made aware. Besides that, food quality should be organic, hygienic and sanitation should be fully maintained, respective behavior should be done with tourists, reasonable price with quality service. Tourism sectors should promote the typical culture also.

Fifth Stage: Monitoring of service quality sensitize the service providers on their service quality. The study found that there is no provision of hiring the external expert to check the service quality of hotel or home-stay by the operator of hotel or home-stay. They have internal assessment system. The monitoring from government level or from tourism business related association or from tourism board found very weak so it should be strengthen and need to check the Total Quality Management-TQM against the basic standard of home-stay or other services. Monitoring team should have technical skill to provide the constructive feedback to correct the lacking. Monitoring should also encourage the service providers to provide the best service quality.

Sixth Stage: This is the stage of regular improvement in service quality. There is no stage of perfection or saturation. This is the time of technology; every second, there may be new findings and products in the market. Everything need some improvement and change as the need of market so tourism sectors should regularly improve their quality on the basis of feedback of monitoring team, tourist or from their own past experiences. Public hearing can be done to get the feedback for the improvement.

Seventh Stage: In the final stage of the model, rural tourism should focus on the development of rural community. Tourism is not related with the development of individual household but it contributes in the development of whole society with the active mobilization of local resources. Other potential business sectors should be promoted side by side to develop the community. The result of this study found not so satisfactory change in development of social activities; health, education and social life-style. It is the corporate social responsibility (CSR) of tourism sectors to promote the other opportunity of rural community with the active public participation.

The study was based on the quantitative design following the philosophy of post-positivist. Post-positivist see the critical reality of finding of study so to ensure the reliability to finding of quantitative analysis, some qualitative discussion was also held. The study had conducted interview with home-stay operators during the data collection in the field and some relevant story are analyzed to support the findings of the survey. The case of each district showed the impact of home-stay to change the socio-economic status of home-stay operators. The idea of in-depth interview supported to develop the model of tourism development.

The home-stay operators also realized the need of further improvement of home-stay to increase the number of tourists. The study discussed with Mr. Jogeshwor Tharu, permanent resident of Amaltari, Nawalparasi who was doing home-stay business since 2013 and was supported by his family members. Before starting this business, he worked as tourist guide in Chitwan National Park. Around 5 years he worked there and got a tremendous knowledge of tourism. Then, gradually, the concept of home-stay came in their community also and his neighbours started home-stay which inspired him to be self-employed. As their suggestions, he also started home-stay. He had no economic problem to start home-stay because he had saved some money from his past job so he renovated his old house and decorated with new furniture. He visited tourism board to know some basic requirements of home-stay and got idea of basic standard of home-stay. He said that he properly followed the basic standard during the construction phase and continuously following these standards. Then he was earning monthly around NRs. 30000/which was sufficient to manage his household expenditures.Besides the benefits of home-stay, he also shared that there were challenges to run the home-stay. He said that the security of tourists in the tourist destination was the major problem and frequent road strike from political parties and inadequate facilities of electricity were also creating problem to increase the size of tourists. So he requested to the concerned authority and Nepal Government to support us by providing the security to the tourists and need to develop the basic infrastructure facilities in the 
tourist destinations to extend their service in future also.

4. Conclusion

There are different Theoretical aspects of tourism development in different context. Many previous theories describe the development of tourism in a cyclical pattern. Because of the changing nature of the tourism market and the changing tourists' motivation affect the changes in the tourism market. But there are important role of economic, social, or physical factors also to promote the rural tourism. In the context of Nepal, geographical constraint, lack of access of road, electricity and communication are the challenges to promote the rural tourism. Considering these basic requirement, the study has developed the community oriented rural tourism development model (CO-RTDM) having with seven stages of development. First stage talks about the identification of appropriate tourist destination, second stage talks about the need assessment and planning, third stage talks about the infrastructure development, fourth stage talks about the implementation, fifth stage talks about the monitoring of total quality management, sixth stage talks about the regular improvement in service and facilities on the basis of monitoring of total quality management and in seventh stage, it will ensure the rural development from the contribution of rural tourism development. The study has develop the model so further researcher or related stakeholders can test the effectiveness of this model.

References

Butler, R. (1980). The Concept of a Tourist Area Cycle of Evolution: Implications for Management of Resources. Canadian Geographer, 24 (1), 5-12.

Butler, R., \& Miossec, J. (1993). Strategic investment decisions: theory, practice and process. London, New York.

Coenen, L., \& Truffer, B. (2012). Places and Spaces of Sustainability Transitions: Geographical Contributions to an Emerging Research and Policy Field. European Planning Studies , 20 (3), 367-374.

Cottrel, S. P. (2003, Sep 6). Sustainable Tourism Development. Retrieved Dec 29, 2016, from A Dutch International Development Approached: www.nipa.org

Geels, F. (2004). From sectoral systems of innovation to socio-technical systems. Insights about dynamics and change from sociology and institutional theory. Research Policy, 33 ( 6-7), 897-920.

Geels, F. (2002). Technological transitions as evolutionary reconfiguration processes: a multi-level perspective and a case-study. Research Policy, 31 (8-9), 1257-1274.

George, E., Mair, H., \& Reid, D. (2009). Rural Tourism Development Localism and Cultural Change. Toronto: Chanel View Publications.

Gunn, C. A. (1994). Tourism Planning: Basic concepts cases',. Washington, DC.: Taylor \& Francis.

Henderson, J. (2009). Transport and tourism destination development: An Indonesian perspective. Tourism and Hospitality Research, , 9 (3), 199-208.

Khadaroo, J., \& Seetanah, B. (2008). The role of transport infrastructure in international tourism development: A gravity model approach. Tourism Management, 29 (5), 831-840.

Leiper, N. (1990). Tourist attraction system. Annals of Tourism Research, 367-384.

Lew, A. A. (1994). A Framework of tourist attraction research. In J. R. Goeldner., Travel, Tourism and Hospitality Research (2ed) (pp. 291-297.).

Lew, A. A. (1987). A model of tourist attraction research. Annals of Tourism Research, , 14, 553-575.

Pao, J. (2005, may 19). A Review of Economic Impact Analysis for Tourism and Its Implications for Macao for Macao. Monetary Authority of Macao. . Retrieved Dec 29, 2016, from worldwide web site;: www.amcm.gov.mo/publication/quarterly/../Econ.impact_en.pdf.Accessed:

Reisinger, Y., \& Turner, L. W. (2003). Cross-Cultural Behaviour in Tourism. Butter- worth Heineman: Oxford.

Randelli, F., Romei, P., \& Tortora, M. (2012). An evolutionary model for the rural tourism study: the Tuscany case. Annali del turismo , 1-20.

Roberts, L., \& Hall, D. (2001). Rural Tourism and Recreation: Principles to Practice. Wallingford, CABI.

Streimikiene, D., \& Bilan, Y. (2015). Review of Rural Tourism Development Theories. Transformations in Business \& Economics , 14 (2 (35), 21-34.

\section{Copyrights}

Copyright for this article is retained by the author(s), with first publication rights granted to the journal.

This is an open-access article distributed under the terms and conditions of the Creative Commons Attribution license (http://creativecommons.org/licenses/by/4.0/) 